\title{
Supplier Developmet: Theories and Practices
}

\author{
Rajendra Chavhan ${ }^{1}$, Dr.S.K.Mahajan ${ }^{2}$, Joshi Sarang P. ${ }^{3}$ \\ ${ }^{1}$ (Mechanical Engineering, Government Polytechnic College, Bandra, Mumbai, India) \\ ${ }^{2}$ (I/C Director, DTE Maharashtra, Mumbai, India) \\ ${ }_{3}^{3}$ (Operations-Fellow Student, National Institute of Industrial Engineering, Mumbai, India)
}

\begin{abstract}
The purpose of this paper is to find out current supplier development practices employed by different organization. Paper mainly focuses on supplier development, supplier development activities, programs, critical elements and beneficial move by buyer. Importance of relationship development and factors responsible for it long with current gaps in this field is discussed in brief.
\end{abstract}

Keywords: supplier development programmes, supplier development factors, relationship development, supplier training, supplier development process.

\section{Introduction}

Growing competition forces firms to reduce their cost with improved quality and service. However traditional approaches have been limited to eliminating wastage within an enterprise. Another way has now opened up through supplier development. Cooperation with suppliers can make buyer more efficient and thus enable goods to be purchased at lower prices and also makes buyer to look for his core competency to remain more competitive. A growing body of literature suggests that a company will perform well if it collaborates with suppliers in new product development (NPD) and Suppliers Development Programme [1].

The term "Supplier Development" was first used by Leenders (1966) to describe efforts by manufacturers (Buyer) to increase the number of viable suppliers and improve supplier's performance. More specifically supplier development has been defined as "any effort by an industrial buying firm to improve the performance or capabilities of its suppliers" [2]. Much of the supplier development literature focuses on the automotive industry either in the US, Europe, Japan or elsewhere and is performed primarily on large firms. This is especially true in the automotive manufacturing industry in view of the fact that in the automotive industry up to $75 \%$ of the cost of a vehicle comes from parts sourced from outside suppliers [3]. Hence auto firms cannot be competitive in the world market unless they deal with suppliers who share similar objectives and have the same level of performance. So to help suppliers to make them more competitive and efficient will automatically helps buyers to become more competitive and efficient.

Supplier development refers to an organization's efforts to create and maintain a network of competent suppliers. From a narrow perspective it can be defined as identifying new sources of supply where no adequate ones exist. However supplier development also involves a long-term cooperative effort between a buying firm and its suppliers to upgrade the suppliers' technical, quality, delivery, and cost capabilities and to foster ongoing improvements [4]. Simchi et al. (2000) in their book of designing and managing the supply chain- concepts strategies and case studies categorized levels of supplier integration as none, white box, gray box, and black box as per increasing involvement[5].

Due to increase in competition inventory reduction and staff downsizing many buying firms are sticking only to their core competencies which in turn provide solution as outsourcing a large part of the buying firms' activities. This results in additional responsibilities of various kinds such as managing inventory for customers, earlier participation in product development, producing near-perfect quality, delivering smaller lot sizes to narrowing delivery windows, providing steady price reductions and more on the shoulders of suppliers. Due to such additional responsibilities suppliers are now considered an extension of the buying firm's organization. Such a changing role of supplier is probably the reason why Laugen et al. (2005) identify supplier strategy as one of the emerging best practices of buying firm [6].

\section{Literature Review}

By understanding literature it has classified on the basis of supplier development process, supplier development programmes, supplier development activities, important factors identified for supplier development, beneficial move from buyer to remain competitive with starting what is supplier development.

\subsection{What Is Supplier Development?}

Literature of supplier development activity is based on three widely used definitions. The first definition by Watts and Hahn (1993) refers to supplier development as "A long-term cooperative effort between 
a buying firm and its suppliers to upgrade the supplier's technical, quality, delivery and cost capabilities and to foster ongoing improvements". This definition deals with long term commitment and relation between supplier and buyer and as per increase in relation and commitment. Improvement from supplier side will make supplier more efficient and capable and will give additional competitive advantage to buyer to become more competitive. This definition did not strongly mention that supplier development strategies need to be supported by both buyer and their suppliers. This dual relation was effectively described later by Krause and Ellram (1997) to extend the scope and purpose of supplier development. Second definition is often referred in the academic literature as "Any effort of a buying firm with its suppliers to increase the performance and/or capabilities of the supplier and meet the buying firm's supply needs". Here Krause and Ellram recognize that supplier development is intended to help the supplier to enhance its performance and/or capabilities for the sake of buying company. But here they did not mention about the time period i.e. it should be long term or short term or goal oriented. As per first definition supplier development is a long term strategy that is based on cooperation between the buying company and this is missing in second definition. A third definition defines supplier development as "Any activity a buyer undertakes to improve a supplier's performance and/or capabilities to meet the buyer's shortterm or long-term supply needs" [8]. Based on the three definitions provided and available literature we can say that supplier development is "A long-term cooperative strategy initiated by a buying organization to enhance a supplier's performance and/or capabilities so that a supplier is able to meet the buying organization's supply needs in more effective and reliable way which will give additional competitive advantage to buyer to become more competitive in market".

There are some problems faced by buyer from suppliers like current suppliers is not providing product that was demanded by buyer, suppliers are either not performing up to expectations or requirements, quality provided by supplier is not making buyer competitive, buyer is facing problem due to non availability of capable suppliers in market. For such problems there are mainly 3 solutions as follows.

Supplier switching - Buyer can search another supplier which is more capable, Vertical integration - Bringing the needed product in-house by acquiring the supplier or setting up manufacturing capacities internally, Supplier development - Here buyer has to support the suppliers and help to enhance the product i.e. by providing helping hand to supplier buyer can give chance to supplier for improvement in his capabilities. Currently 3rd option is becoming more important and feasible because it is quite difficult to search for more capable supplier and to make components in house is big investment. So supplier development is emerging and feasible solution to buyer for his mentioned problems [8].

\subsection{Supplier Development Process}

Hartley and Jones (1997) have focused on supplier development processes and they found supplier development as a four step process as, assess the supplier's readiness for change, build commitment through collaboration, implement system-wide changes, transition out of the supplier's organization, establish follow-up and recognition procedures [9].

Handfield et al. (2000) in their article of "Avoid the Pitfalls in Supplier Development" proposed a process map for supplier development. They mentioned 7 steps for supplier development such as identify critical commodities, identify critical suppliers, form a cross-functional team, meet with supplier's top management, identify key projects, define details of agreement, monitor status and modify strategies.

\subsection{Supplier Development Programme}

Supplier development programme has primarily two objectives. First is to reduce the problems of supplier by making immediate changes in the supplier's operations and second is try to increase suppliers capability in such a way that supplier will be able to make its own improvements [2]. Later on this study used by Hartley and Jones (1997) in their study of Process oriented supplier development. They focused on 2nd objective and found positive result for supplier development.

Many supplier development programs are results-oriented and focused on solving specific problems of suppliers. These results-oriented programs will make improvements in their suppliers' quality and cost. Resultsoriented supplier development increases the performance of supplier but not helps supplier to increase their capabilities for continuous improvement. From the graph we can easily conclude that process oriented programme is for continuous improvement of supplier over result oriented programme. Result oriented programme also have certain advantages like fast implementation of proven process, quick identification of problem and quick solution which will give buyers side team rich experience to solve successive problems of suppliers but this will have disadvantages like less commitment from suppliers side, limited transfer of continuous process knowledge to suppliers and less improvement in suppliers capability to solve problems on their own [9]. 


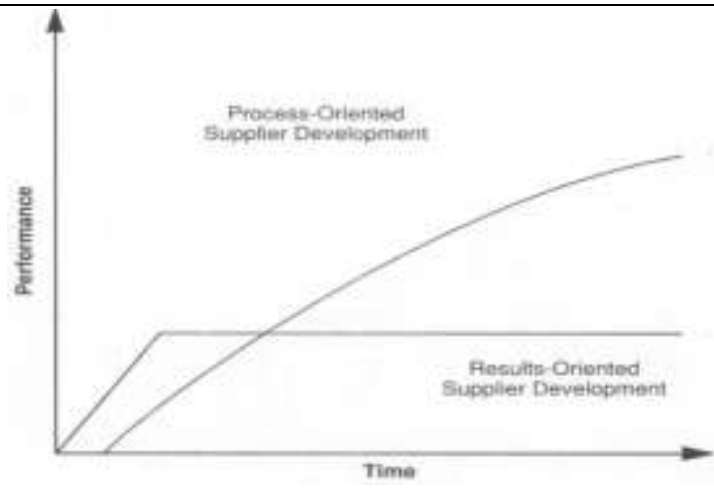

Fig. Graph of Process and Result Oriented Supplier Development

(Source: Hartley and Jones, 1997)

In concern with above mentioned suppliers involvement with respect to process and result oriented approach Che et al. (2008) in his study of adapting buyer-supplier relationship practices in local industry conducted a cross sectional survey and collected data of 26 respondents consisting of officers, engineers, managers and senior managers from various sections within the buying firm's organization. They found that manufacturing firm mainly focuses on supplier development activities requiring little or no involvement from buyer side except its substantial reliance on its suppliers. They also found that buyer is interested in short term result oriented approach in product quality, delivery and cost reduction. Buyer is not fully utilizing the expertise of its suppliers in its product design and development activities and there is a lack of emphasis on the activities that lead to improve the supplier's capabilities i.e. process oriented approach. They also mentioned that limited sample size implies that the findings may not be generalized and this study is conducted in a developing country context and the impact of cultural forces on the success of this programme has not been examined [10].

Wagner (2010) divided supplier development programme into direct and indirect supplier development programme. He found that indirect supplier development improves suppliers' product and delivery performance and that direct supplier development improves supplier capabilities. In indirect supplier development, the buying firm makes use of communication and external market forces to achieve performance improvements on the supplier's side where as in direct supplier development programme the buying firm plays an active role and dedicates its human and capital resources to a specific supplier to solve respective problem. Direct supplier development consists of activities that transfer knowledge and qualifications into the supplier's organization. Examples of such activities are like on-site consultation, education and training programs, temporary personnel transfer and inviting supplier's personnel. He also recommended that at any given time firms should engage in either indirect or direct supplier development not in both [11].

The above parameters also examined by Aslan et al. (2011). They worked on improving short and long term supplier development plan. It is mandatory that before selecting any supplier buyer should make a proper evaluation of supplier by doing frequent visit and if some small issues are coming then by giving required training buyer can select him. To make supplier more efficient in process and quality buyer can start activity with knowledge transfer of operational with suppliers. Collaborative inter-organizational communication is crucial to decrease the problem with suppliers and increase their performances. Many working professional also agree on point that improper communication results in misunderstandings and incorrect strategies. When a supplier see that a firm is doing well and it can still do better if gets some financial help then buyer will invest their limited financial, technical and personal resources on selective bases to suppliers to exploit strategic opportunities for creating value with suppliers. Some incentives can be used to improve performance of suppliers. Currently many buyers are conducting supplier's summit where suppliers can be invited to the firm to see the quality problems related them [12].

Wan et al. (2011) conducted a case study in Isuzu Motor Ltd to study supply chain enhancement through product and vendor development programme (PVD). Here they structured product and vendor development programme in three main components which includes the localization programme, product development and vendor monitoring. They established a team of qualified members with technical knowledge from different departments to execute programme smoothly. Here they found that responsibility of all parties that are involved in the PVD is a key success factor to avoid misunderstanding and delay in decision-making process especially by the PVD team. Involving suppliers in product development can result in major benefits in terms of money and time but it requires a great deal of thinking and effort. Primarily it requires an active management support on behalf of the manufacturer both in the short term and in the long term supported by adequate organizational and human resources for the success of the PVD [13]. 
Supplier Developmet: Theories And Practices

\subsection{Supplier Development Activities}

Sanchez et al. (2005) classified supplier development activities into 3 parts on the basis of buyer's resource involvement parameters like personal, capital and time.

Basic supplier development- Basically this will deal with supplier's evaluation and giving feedback to him. Supplier qualification is having more importance than supplier certification. Supplier base will be less in number with standardized parts and increased volume of business with limited suppliers.

Moderate supplier development- Word itself describes that buyer involvement is of moderate type. This mainly includes activities like rewarding and recognizing supplier's performance, giving visits to suppliers to solve their problems, making supplier efficient in materials based issues and certification of suppliers.

Advanced supplier development- In this case buyers involvement is more in terms of parameters discussed above (capital, time and personal). It includes proper training to supplier involving supplier in design and development of new product, sharing of information like cost, quality and financial data [14].

\begin{tabular}{|l|l|l|}
\hline Basic Supplier Development & Moderate Supplier Development & $\begin{array}{l}\text { Advanced } \\
\text { Development }\end{array}$ \\
\hline $\begin{array}{l}\text { Evaluation of supplier's } \\
\text { performance and feedback to } \\
\text { suppliers. }\end{array}$ & $\begin{array}{l}\text { Visiting suppliers' plants. } \\
\text { Awards and approval of } \\
\text { supplier's performance } \\
\begin{array}{l}\text { Sourcing from a limited } \\
\text { improvements. }\end{array}\end{array}$ & $\begin{array}{l}\text { Training to suppliers. } \\
\text { Collaboration with supplier. } \\
\text { Involvement of suppliers in } \\
\text { the buyer's new product } \\
\text { Parts standardization. }\end{array}$ \\
$\begin{array}{l}\text { Collaboration with suppliers in } \\
\text { Supplier qualification. }\end{array}$ & $\begin{array}{l}\text { development process. } \\
\text { Intensive information } \\
\text { exchange with suppliers. }\end{array}$ \\
\hline
\end{tabular}
Sanchez et al. (2005) also gave some supplier development practices as follows.

Supplier development practices

\begin{tabular}{|l|}
\hline Buying from a limited number of suppliers per purchased item \\
\hline Supplier performance evaluation and feedback \\
\hline Parts standardization \\
\hline Supplier certification \\
\hline Supplier reward and recognition \\
\hline Plant visits to suppliers \\
\hline Training to suppliers \\
\hline Intensive information exchange with suppliers \\
\hline Collaborating with suppliers in materials improvement and development of new materials \\
\hline Involvement of suppliers in the buyer's new product development process \\
\hline
\end{tabular}

Krause (1999) in his study of the antecedents of antecedents of buying firms' efforts to improve suppliers identified important factors that influence firm's involvement in supplier development. Here he found that primary dependent factor in supplier development activity is the buying firm's involvement in supplier development activities and that will play a crucial role. The antecedent to this factor includes supplier commitment, expectation of relationship continuity and effective buyer-supplier communication. Again factors which effectively improve supplier are recognizing and rewarding outstanding suppliers, training and educating supplier's personnel, promising to give more business if supplier performance improves, exchanging personnel between the two firms, direct investment in a supplier by the buying firm. Further Krause et al. (2000) in their study of structural analysis of the effectiveness of buying firms' strategies to improve supplier performance further classified supplier development activities mainly into 4 parts as competitive pressure, supplier assessment, supplier incentive and direct involvement [7].

As per the organization level supplier development activities vary widely. Mainly supplier development activities includes supplier evaluation, feedback of supplier performance, raising performance expectations, education and training for supplier personnel, supplier recognition, placement of engineering, buyer personnel at the supplier's premises, and direct capital investment by the buying firm in the supplier. For example training of a supplier's in statistical process control not only helps buyer to achieve desired quality levels but also makes him more competitive. The buyer has competitive priorities that can be met only through drastic improvements in supplier's capabilities [15].

\subsection{Factors Identification} supplier.

By critical review of literature following factors found to contribute primarily for development of 
Supplier Developmet: Theories And Practices

\subsubsection{Supplier Evaluation}

First step of supplier development is supplier's evaluation because after this buyer can identify areas of supplier where improvement is needed. This step helps to point out exact cause of problem i.e. whether the problem is in material or in design or in production process or in workmanship. Suppliers basically get evaluated on the basis of parameters like technical capabilities, quality, cost, delivery, managerial capabilities. On basis of these parameters suppliers are classified in to groups. So supplier evaluation is integral part of supplier development which serves as a platform for launching supplier development programme. This phase will mention problem of supplier which will be basically related with product, process and operating system. Combining supplier's problem and supplier development programme a matrix will form which will give guideline that which supplier development plan is necessary for which problem [16].

Carr and Pearson (1997) in their study of buyer- supplier's relationship and its outcome on performance found that supplier evaluation provides a better view to buyer regarding which suppliers are doing well and which are not. This also helps buyer to identify where a particular supplier is weak to make improvements. Evaluation also helps buyer to create long-term relationships with suppliers who are doing well and this longterm relationship helps for continuous improvement to remain competitive. Basic parameters for evaluation are quality of product, price delivery, service and support [17].

Cormican and Cunningham (2007) worked on performance evaluation in a large multinational organization. Here they evaluated suppliers based on parameters like on time delivery, quality and total cost. He gave $40 \%$ weight to on time delivery, $40 \%$ weight to quality (Parts per million) and $20 \%$ weight to total cost. Then found the total score by adding score of these 3 parameters and rank suppliers.

On Time Delivery $(\mathrm{OTD})=$ Number parts received on time / Number of total parts expected $*(100)$

Parts Per Million $(\mathrm{PPM})=1000000 /$ Parts Received $*$ (Parts Returned)

Total Cost $=1-($ cost of quality /cost of materials received for the period)

After evaluation, based on these parameters they have reduced their supplier from 23,225 to 8,024 which helped buyer to found best performing suppliers and to eliminate those not doing well. So as supplier base got reduced it helped buyer to come closer to suppliers to build long term relationship. Result of reducing the number and improving the quality of suppliers resulted in increased quality, reduced lead time and reduction in the number of errors and defects [18].

Hald and Ellegaard (2011) in their study of Supplier evaluation processes found that there should be shaping and reshaping of supplier performance to raise quality and to remain competitive. They mentioned 13 different factors on which supplier's evaluation can be sharpened. Factors shaping the design of supplier evaluation systems are evaluation group structure, decision-making authority, performance complexity, assessability/measurability of data. Then factors shaping the implementation of supplier evaluation systems are rating/translation models on supplier performance, buyer logic on how to motivate suppliers, instability of supplier evaluation system, resource consumption in updating data. Then factors shaping the use of supplier evaluation systems are addition of information, failure to benchmark supplier performance, failure to relate to buying company performance, unwillingness to inform suppliers, re-communicating performance data [19].

Again they classified these 13 factors into a set of five generic dynamics as representing, reducing, amplifying, dampening and directing. Representing is act of speaking on behalf of supplier performance. As part of the design phase, representation issue plays a major role in shaping supplier performance. Reducing is act of making an object smaller or less in amount. Here object of reduction is data for evaluation of supplier. This information is useful in directing supplier's effort. Amplification is act of making an object more marked or intense. Here buyer amplifies drawbacks of suppliers for improvement. This step should be handled in such a way that supplier should not get demotivated. Dampening is an act of restraining or depressing an object. By dampening the signal buying company may succeed to some extent in restoring face and goodwill but can create confusion for evaluated suppliers in terms of accuracy, reliability and seriousness of the entire evaluation exercise. Directing is act of assigning a route for an object. If directing goes in correct direction then it can create drastic performance improvement in supplier [19].

Azadegan (2011) in his study of benefiting from supplier operational innovativeness with the influence of supplier evaluations and absorptive capacity found that supplier evaluation programme (SEP) and absorptive capacity are both means to increase operational innovativeness (OI) of supplier. Supplier evaluation programme by buyer with good direction helps to encourage operational innovativeness of supplier which helps buyer to remain competitive. Author used evaluation parameters as product development and quality, manufacturing design and capability, manufacturing and design capacity. Operational innovation mainly relates with process improvement, new tool with higher speed, new product development and new concept. He also found absorption capacity influences operational innovativeness. Absorption capacity mainly includes routine search, new technology, learning from supplier and customer, communication and personal adequacy. For increasing innovativeness of supplier evaluation should be effective. Effective evaluation should have incentives i.e. for suppliers who are doing good innovation buyer should recognize and reward to increase confidence and motivation of supplier. Also effective evaluation should have proper assessment [20]. 
With regarding to innovation of supplier Schiele et al. (2011) in their study of supplier innovativeness and supplier pricing found that technical capability of supplier affects greatly on innovation. Regarding pricing policy they found that when supplier is having awareness of his innovation and capabilities than he might charge unfair price to buyer while preferred customer status may change this behavior and lead to more benevolent supplier pricing behavior so they state that preferred customer status has positive impact on supplier innovativeness. Their parameters for preferred customer were like this supplier has made sacrifices for us in the past, supplier cares for us, supplier has gone out on a limb for us in case of shortages, we feel this supplier is on our side, the best resources of this supplier work for us [21].

Prior to this Charterina and Landeta (2010) in their study of pool effect of dyad based capabilities on seller firms' innovativeness found that as relationship goes on increasing with increased trust and resource interdependence which has started from contracts leads to encourage the exchange of knowledge, specialized resources and specific investments. Due to this effect firms come closer with committed relationship which leads to innovation. They found that for improving supplier innovation investment in specific assets for the customer-supplier relationship is more effective i.e. as exchange of knowledge, investment in specific assets and efforts to pool resources, increases trust, interdependence and commitment which lead to innovation [22].

\subsubsection{Early Supplier Involvement}

Earlier buyers were supposed to do design and suppliers were following these design. Here suppliers were finding some problems in design complexity also while designing any components there were many chances that buyer will not take care of suppliers technical capacity due to which it becomes difficult for suppliers to make control over process and quality. Then the concept of early involvement of suppliers has come which also gives additional advantage of suppliers innovativeness to buyer. The qualifications in terms of product quality, delivery capability, compatibility of production processes, technical capability and financial strength of suppliers have a positive effect on suppliers' performance. The early involvement of suppliers decreases the cycle time of product development. The most important stage of involvement is design stage and mistakes in this stage may be costly in further stages. If suppliers are involved in the market testing they can know better customers' expectations and they can increase the satisfaction level of them. This involvement will develop the supplier's capabilities and this can result in a long-term relationship [23].

Twigg (1998) in his study of managing product development within a design chain in UK automotive industry identified supplier involvement during different phases as follows.

At concept stage- This phase comes before design and mostly consultants and specialist play major role in this phase. For example innovating or developing new product.

During detail engineering stage- Here supplier is capable to design and manufacture product with required quality and specification of buyer but concept and required features are given by buyer. Multinational component system suppliers may take responsibility during this phase. Material producers also have a role to play in design with regard to the properties of new materials or their application.

For the process engineering stage- Here manufacturing knowledge is essential for supplier. Toolmakers, equipment manufacturers, raw material suppliers or process specialists have an important role to play in this stage. Design is given by buyer and supplier's role is to manufacture component as per drawing with required quality [24].

McIvor and Humphreys (2004) in their study of early supplier involvement in design process in an electronic industry found that involvement of supplier by buyer in mentioned phases depends on culture in both organizations. Culture depends on parameters like supplier involvement in new product development buyersupplier relation and communication exchange and other than this trust and commitments are also essential. He also listed some major barriers for Early Supplier Involvement (ESI) as buyer playing suppliers off against each other for good outcome, lack of clarity and inconsistencies in the policy guidelines for the level of supplier involvement, top management not supporting to ESI team at local level, resistance from design personnel in increasing the level of involvement of suppliers in the design process, conflict between members of the integrated product development team, suppliers are suspicious of the motives of the company when requesting cost information, Some suppliers may not be confident enough of the accuracy of their costing structures to share them with their buyer, Not enough dedicated resource in the company to jointly work with key suppliers, Annual contract negotiations and Culture difference [25].

Jiao et al. (2008) performed a case study on operational implications of early supplier involvement in semiconductor manufacturing firms. Here they mentioned major barriers for early supplier involvement and possible solutions as follows.

The dependency on reliable and technically competent suppliers to satisfy completely the objective: Solution for this problem is good and well defined selection criteria. This will assess not only the technical capabilities of the suppliers but also their reliability in delivering goods on time and in the promised quality.

Unwillingness of suppliers to provide the increased level of support: Major reason for this problem is due to bearing greater risk/increased responsibility, commitment from the buying company, company size of the 
suppliers and supplier-buyer relationship (supplier goodwill). Solution for this problem is to use reward sharing agreements.

Lack of motivation from the staff of the company: The suggested solution is profit-sharing. Top management also plays an important role in creating a motivating and competitive environment to encourage their people to put in their best efforts. They should always push for improved manufacturing process, reduced lead-time and reduced manufacturing cost.

Problems relating to the ownership of the jointly developed design/product: Such problems are difficult to resolve once co-operation starts. This problem may be solved through reaching an agreement in advance.

Fear of leaking proprietary information: Proprietary information such as demand figures, detailed material specifications and equipment information is often highly confidential. By passing such information to suppliers the company takes a risk of losing its competitive advantage to rival companies. Making use of non-disclosure agreements is possible solution.

Poor communication: Proper means of communication must be established so that any ESI efforts will not be hindered by the miscommunication of information.

Perceived higher cost in involving their suppliers earlier: Involving suppliers earlier is costly due to reasons like cost incurred in setting up common information systems, cost incurred to provide training to the suppliers so that the quality control of materials can be improved at the suppliers' plants, rewards and incentives to motivate the suppliers, co-design expenses incurred and investments in supplier's plants so as to improve on materials at the source. To resolve this issue top management has to understand that no company can exist on its own. Its survival is directly dependent on its suppliers. Hence investing in their suppliers will eventually benefit them in the form of better technologies and greater security in the procurement of good quality materials. So for better result of early supplier involvement supplier should be capable, should be committed and faithful [26].

Eisto et al. (2010) in his study of early supplier involvement in new product development in a casting industry found that early supplier involvement benefits in time and cost saving with improved quality [27].

\begin{tabular}{|c|c|c|}
\hline Time Saving & Cost Savings & Improved Quality \\
\hline 4 & & 4 \\
\hline $\begin{array}{l}\text {-Reduced need for additional } \\
\text { Clarification } \\
\text {-Customer order get prepared } \\
\text { earlier } \\
\text {-Improvement in process }\end{array}$ & $\begin{array}{l}\text {-New improved solution } \\
\text {-Easy handling of finished part } \\
\text {-Reduced time }\end{array}$ & $\begin{array}{l}\text {-Material Choice } \\
\text {-Reduced rejection } \\
\text {-Dimension and quality as per } \\
\text { requirement of buyer }\end{array}$ \\
\hline
\end{tabular}

Source: Eisto et al., (2010)

The level of involvement of suppliers increases with supplier's innovation, valuable knowledge and expertise. Supplier involvement increases the quality, reliability, delivery, processes flexibility and customer service with decrease in cost which brings competitive advantage to buying firm. Moreover short time to market with collaboration will bring another strategic advantage. The role of supplier at design, production and service is crucial for innovation, new design as per demand of customer, development in process, and short time to market [28].

\subsubsection{Supplier Training}

Programs for supplier development that receive assistance from buyers can be regarded as buyer supported training. The literature suggests that buyers have various ways of supporting their suppliers with some buyers giving more support than others. Some buyers focus on short-term benefits while others look at supplier development as a long-term investment. Thus suppliers have access to different types of supplier development programs depending on their buyers. This implies that the types of training that would most benefit suppliers could be best assessed through studies focusing on the supplier perspective. By identifying the relevant types of training buyer-supported training programs could increase. This would be because buyers could select the type of training suitable for specific groups of suppliers. The right type of training could then lead to an increase in performance for the supplier which would in turn encourage an increase in buyer-supported training. Buyer may send his employees or group of team to train supplier or he may invite group of suppliers facing same problem for training in his own firm [29].

Kadir et al. (2011) made a case study in Malaysian automotive industry on Patterns of Supplier Learning. Here they found that supplier development programs support the development of a supplier's capabilities usually with the assistance of a buyer. Supplier development also depends on supplier's interest and how they explore them self to increase their capabilities. Although local suppliers do receive assistance from their buyers but this type of assistance is still not adequate to improve supplier capabilities. Therefore analyzing environment that provides buyer-support training could help to identify factors that suppliers themselves seem important for development of their capabilities. It is claimed that support from buyers for supplier training has been deficient. Thus there is a need to identify the types of training that suppliers themselves prefer. Buyers 
themselves have significant knowledge of the training that a supplier might need but as technology development happens the buyer no longer has a hold on all of the technology that is involved or coming. Thus it is important that suppliers looking to develop their capabilities have access to the type of training that they require which may or may not be provided by their buyers. For suppliers that have access to buyer-supported training their training needs might often change as they develop their own capabilities [30].

\subsubsection{Communication}

Eamonn et al. (2008) in their study of selection of communication media in buyer supplier relationship found that communication media selection is affected by need of participants and stage of relationship. If relationship is new then communication media will be face to face for more clarity in communication. As relations goes on increasing media choice becomes less rich focusing on either telephone or email depending on the needs of buyer or supplier. As relationship reaches to mature stage face to face media is preferred to take advantage of richness and which also helps to take social benefit of relation. They also found that in product purchasing buyer is more central to the relationship and has greater influence over the communication media choice and buyer is interested in informal communication like telephone communication. In case of service purchasing buyer is less central to relationship and for communications he uses legalistic means such as email [31].

Study of Sanders et al. (2011) indicate that buyer-to-supplier information sharing, buyer-to-supplier performance feedback and buyer investment in inter-organizational information technology are key enablers of buyer-to-supplier communication openness. However only buyer-to-supplier communication openness plays the direct and critical role in achieving significant performance improvement. They mainly focused on openness in communication and openness acts as a key parameter for supplier improvement and this improvement will mainly move in the direction that buyer wants [32].

\subsection{Beneficial Move from Buyer}

\subsubsection{Supplier Relationship}

Firms have realized that collaborative business relationship improve firm's ability to respond to the new business environment by allowing them to focus on their core businesses and reduce costs in business processes. According to Sheth and Sharma (1997) following four reasons contribute for buyers to develop better supplier relations. First marketers or sellers are driving this change as firms have started identifying and catering to the needs of specific customers. Thus having a relationship with suppliers will enable firms to receive better service and therefore procurement will be more efficient. Second, for improving quality of product it is easy for buyer to implement strategies such as quality platforms if firms have relationships with their suppliers. Third, as choice and demand of customer are changing rapidly buyer alone can't fulfill it or due to limitations he can't become strong in all areas of technology. So it is better for buyer to maintain good relation with suppliers having strong technical capabilities in respective areas. Finally competition and the growth of alliances are forcing firms to develop better supplier relationships to maintain a competitive edge [33].

To build relationship between supplier and buyer trust plays a vital role. Smeltzer L (1997) in his study of meaning and origin of trust in supplier-buyer relation gave some parameters which indicates trusting environment between supplier and buyer. These were follow through, exchange of information i.e. new idea from supplier side, listening and reacting to suppliers problem, open communication to avoid misunderstanding, mutual respect, sharing of cost savings, honesty, knowledge about product, positive attitude, good past performance, priorities, effort, sharing of technical advantages [34].

Building and maintaining close relationships- McCutcheon and Stuart (2000) in their study of issues in the choice of supplier alliance partners found that manufacturer is interested primarily in desirability and the feasibility of partnership. Desirability mainly deals with the suppliers technical capabilities and supplier should satisfy technical and operational requirements of buyer. Feasibility mainly deals with goodwill, trust and benefits [40]. Johnston et al. (2004) also found that trust plays a vital role to develop and maintain relations between supplier and buyer. A critical element in achieving supply chain effectiveness is establishing and nurturing trust across the organizational boundaries particularly for relationships such as alliances between buyers and suppliers in a supply chain [35].

In terms of relation improvement Johnston et al. (2004) in his study of effects of supplier trust on performance of cooperative supplier relationships found that higher levels of inter-organizational cooperative behaviors such as shared planning and flexibility in coordinating activities were found to be strongly linked to the supplier's trust in the buyer firm [35].. Like Customer Relation Management (CRM) Supplier Relation Management (SRM) is emerging and it is important from buyer's perspective to develop good supplier relation to remain competitive. Literature on buyer-supplier relationships has classified into two categories cooperative and competitive. Cooperative relationships are characterized by a long-term commitment, shared common goals, two-way information sharing and a high level of trust while competitive relationship is fast result oriented process [36]. 
Li (2006) in his study of relationship learning found that for competitive advantage relationship learning is an important avenue for creating differential advantage and supernormal profits in relationships. He found that firms should build up commitment towards a learning relationship by a) invest time and effort when formulating common objectives with the specific visiting client b) implementing actions related to those objectives and c) monitoring achievement of such objectives. This says that relationship learning is becoming a major mechanism to facilitate cooperative performance [37]. Goffin et al. in 2006 also worked on close' supplier-manufacturer relationships and divided type of relationship mainly in 3 parts as follows.

The appropriateness of close relationships- Petroni and Panciroli (2002) in his study of innovation as a determinant of supplier's roles and performances studied 198 suppliers operating in the food packaging machinery industry. They recommended that the supplier base should be managed as a "portfolio" of relationships. Here suppliers are classified on the basis of parameters like involvement, innovativeness, quality, delivery, performance, type of components, loyalty, and new product development [38, 39].

The nature of close relationships- Lambert et al. (1996) in their study of developing and implementing supply chain partnership found that closeness is supposed to be important characteristic in relation building i.e. more is the closeness strong is the relationship. They also state that partnerships are closer than other types of relationships. Partnership model alone will not work effectively along with that manager should provide some incentives and reward to build close relationship. Top management should recognize and reward co operative behavior [41].

Li et al. (2007) in their study of supplier development efforts on buyer's competitive advantage found that trust and joint action are appear most critical elements to enhance the operational effectiveness of a buyer while asset specificity improves the market responsiveness of a buyer slightly. They also stated factors contributing for increasing good relations between supplier and buyer as follows.

Trust and Commitment to Long-term Goals: Both suppliers and buyers need to demonstrate trust and commitment towards long-term vision. Trust and commitment are major predictors of successful relationships.

Mutual Benefit: The relationship should be of benefit to both the buyer and the seller. If the relationship has one-sided benefits then the relationship will not last.

Top Management Support: Most successful relationships are associated with support from the top management of a firm.

Compatible Organizational Culture: The culture of firms should be compatible. This suggests that they share common values and share common reward systems.

Sharing of Information: Relationships require sharing of information. The benefits of relationships arise from reducing the uncertainty associated with transaction oriented exchanges. Information increases certainty and reduces needless interaction.

Strong and Open Communication: Strong and open communications reduces misunderstanding and enhances the quality of relationship.

Simple and Flexible Contract: Simple and flexible contracts enhance relationships as they are used as guides rather than specifying all contingencies.

Intensive Management Involvement: Cross functional teams from both the supplier and buyer organizations should meet periodically to enhance their relationships.

Periodic Performance Monitoring: Performance monitoring is critical element for relationships. Suppliers also appreciate a formal performance evaluation method.

Internal Controls: It is intuitive but companies need to protect access and distribution of confidential information with rigorous internal control.

Problem Solving Procedures: Companies need to establish problem solving procedures that reduce conflicts or prevent conflicts. One of the simplest forms is frequent communication at all levels of the customer and supplier organization [42].

Hosmer (2008) gave six ethical elements contributing to relationship improvement.

1) Personal virtues: - Openness, honesty, and truthfulness are required to eliminate distrust.

2) Religious Injunctions: - Treatment as a valued partner leads to reach common goal easily.

3) Utilitarian Benefits: - Relationship should benefit both parties and society without harming any one.

4) Universal Rules: - Relationship should be legal and honest in every way.

5) Distributive Justice: - Never take any action which would harm anyone.

6) Contributive Liberty- No one should ever interfere with the rights of anyone to improve their legal abilities or their marketable skills associated with self development and self improvement [43].

Gullett et al. (2009) in their study of buyer-supplier relationship identify how six ethical elements mentioned above contribute for framing the buyer-supplier relationship. They also found that trust plays a vital role in relationship building and he mentioned trust depends mainly upon following parameters like communication, task competence, quality assurance, interactional courtesy, legal compliance and financial balance [44]. 
Hald et al. (2009) in their study of understanding of attraction in buyer-supplier relationships found that mutual attraction is important in relationship development and major components of attraction are trust, expected value and dependence. Further they classified components of trust, expected value and dependence as follow.

Trust: - They mentioned trust as benevolence trust and integrity trust. Benevolence is the extent to which a trustee is believed to want to do good to the trustor and it mainly affected by loyalty and support. Integrity trust depends on shared values, reliability and fairness.

Expected Value:-They classified expected value in 2 categories as buyers and suppliers expected value. Buyer mainly expects cost reduction, innovation and time compression where as supplier expects price/volume and growth.

Dependence: - It is degree to which a buyer or a supplier needs to maintain the relationship with a supplier or a buyer in order to achieve desired goals. It mainly depends on expected association value, associate alternatives, level of transaction specific assets [45].

While speaking about co-operation it leads to improvement and it should be from both sides. Ana et al. (2011) in their study of competitive effects of co-operation with suppliers and buyers in the sawmill industry found that co-operation between buyer and supplier benefits in terms of productivity and organizational performance. They found that co-operation leads to increased productivity and performance but from only buyer's side not from supplier's side. They stated that co-operation varies with the variables like type of industry, firm size, firm's position in the supply chain, supply chain length [46].

With the parameter of trust on relationship Wagner et al. (2011) in his study of buyer-supplier relationships found that trust during the project collaboration has a stronger influence on future of buyer supplier relationship. At start reputation of supplier on buyer is main parameter for future relationship but when parameter of output fairness is added effect of reputation get partially mediated and when parameter of trust is added effect of reputation and outcome fairness completely get mediated. So trust plays a very important role for further buyer-supplier relationship [47].

Brown et al. (1994) in their study of Dynamics of Partnership Sourcing found importance of partnership for buyer and supplier to come close and to remain competitive. They told that partnership helps Japanese to remain more competitive in their partnership they not only share sensitive information on costs and swapping staff but also helps each other out during periods of economic difficulty and such incidents increases their closeness in relationship. They mentioned some parameters for partnership like purchaser commitment and supplier loyalty, improvement in quality, openness, communication. They also mentioned that based on such parameters partnership vary from supplier to supplier [48].

The two parties use trust as their basic and interdependent support model and thus called "partnership". A good relation existing between the two can be termed as the tightness of the partnership. Wu et al. (2011) in their study on relationship among supplier capability, partnership and competitive advantage proved that supplier capability can be more increased by partnership which directly influence on competitive advantage [49].

This relationship learning is used by $\mathrm{Wu}$ at el. (2011) in their study of mediating effect of relationship learning on the relationship between supplier developments strategies and raising competence found that supplier assessment and direct involvement significantly enhance the relationship learning. Supplier assessment and direct involvement were found to be effective supplier development strategies

\subsubsection{Modularization}

In operation management modularity means that parts or components of a product are sub divisible into modules that can be easily interchanged and replaced. To avoid the complexity in design and sourcing assembly wise part modularization strategy becomes important step but this is a quite challengeable task in front of buyers and suppliers. Modularity is a broad concept applied basically in product design and manufacturing for reducing the complexity of products. Based on well-defined interactions or interfaces between modules modular designs allow design change in one module without changes in other modules. Here complex development task are decomposed into simpler elements that can be developed independently yet operate as a whole. Modularization means product architecture can be decomposed into loosely coupled vs. tightly coupled components offering considerable scope to outsource design and delivery responsibility to suppliers [50].

This concept of modularization along with supply chain is explained by Howard and Squire (2007). They found that modularization will lead to greater levels of buyer-supplier collaboration. Product modularization leads to greater collaboration because of two mediating factors which are asset specificity and information sharing. Buyer and supplier firms should move towards closer collaborative practices in order to codevelop products and reduce interface constraints. Collaboration particularly technical collaboration between buyers and suppliers is important because it can remove the interface constraints encountered during the early design phases of modularization. This will create high dependence between supplier and buyer and will improve relation between them [51]. 
Supplier Developmet: Theories And Practices

Squire et al. (2008) in their study of effect of supplier manufacturing capabilities on buyer responsiveness found that supplier's capabilities in terms of flexibility, responsiveness and modularity which directly impact buyer responsiveness. Here he divided Supplier flexibility in two dimensions (1) Volume flexibility- The ability to operate at different production levels efficiently and effectively (2) Mix flexibilityThe ability to produce different combinations of products efficiently and effectively. Responsiveness denotes the speed with which the supplier reacts to information from the buyer firm. For modularity they stated that supplier modularity enable the buyer to be flexible to changes in customer specifications without increases in cost or reduction in flexibility. They found that supplier manufacturing capabilities significantly influence a buyer's manufacturing performance and collaboration strengthens the contribution of supplier responsiveness to buyer responsiveness but weakens the relationship between supplier modularity and buyer responsiveness They did this study in UK manufacturing firms across eight industry sectors [52].

Regarding modularization in car assembly Joongsan and Rheein (2010) in their study of influences of supplier capabilities and collaboration in new car development on competitive advantage of carmakers found that modularization capability plays a vital role in making carmaker more competitive. They also found that advantage of modularization in car assembly for the several reasons like modularization helps to shorten the cycle time by making assembly process easy with increasing modularization carmakers can reduce costs by outsourcing only to those suppliers who are capable of meeting their requirements. It is easy to look for raising the quality of each module which will help to increase quality of car. Another aspect of modularization is that supplier has to become active in research and development process and this increased R\&D capability of supplier will make supplier-buyer relation close and this will help car makers to remain more competitive in car market [53].

\subsubsection{Global Sourcing}

For buyers to fulfill customer's increasing demand and to remain competitive in market with cost it is mandatory for buyers that their suppliers should supply with low cost and good quality. So currently majority of big firms are moving towards global sourcing for searching equally good product with reduced cost. During the last decade the emergence of total competition in the global market has forced an increasing number of firms to search for the most effective utilization of new technologies and resources dispersed worldwide. One area where companies can begin to capture the benefits of globalization is global sourcing. Global sourcing has main benefit of buyers in terms of low cost. For own equipment manufacturers (OEMs) in auto industry low-cost sourcing became a trend in the beginning of the year 2000 and many companies that previously sourced locally started to investigate the possibilities to replace some share of their current suppliers with suppliers in low-cost countries. Global sourcing is an increasingly popular business strategy but it's not easy to execute. There are seven typical characteristics of organizations with outstanding global sourcing. These are executive commitment to global sourcing, rigorous and well-defined processes, availability of needed resources, integration through information technology, supportive organizational design, structured approaches to communication and methodologies for measuring savings [54].

Takala et al. (2007) in his study of global manufacturing strategies require "dynamic engineers"? Studied the competitive priorities of manufacturing strategies in four different types of industries. Many companies utilize the developing countries as the means of lowering cost but each type of company should have its own special strategy in a holistic way to make global sourcing as a tool for cost and productivity competitiveness. A manufacturing strategy based on a business strategy includes three objectives as competitive priorities, manufacturing objectives and action plans. Competitive priorities relates to cost, quality, flexibility and delivery. Manufacturing objectives relates to performance measures and action plan relates to improvement programs and recognizing its expected effects on specific operating objectives. For such development stages to carry out effectively there is need of trained dynamic engineers in industrial engineering and management and these dynamic engineer will really be the decision maker for the future world-class industries [55].

Oke et al. (2009) in his study of Criteria for sourcing from developing countries studied criteria for choosing amongst suppliers in different developing countries and made study involving 6 case studies. Based on major parameter of cost developed countries source from developing countries and low cost structure plays prime role in competition for businesses and outsourced operations between different developing countries. Major parameters for selection of suppliers are cost, delivery, quality, production facilities and capacity. They found that cost remains a primary criterion for choosing amongst developing countries and suppliers. Physical and cultural proximity also found to be effective due to low transaction costs, low logistics cost, low learning curve, responsiveness, accessibility and the need to patronize local firms to improve company image locally. Quality and reliability are key differentiators for selecting amongst prospective suppliers in a chosen developing country. They also stated that Political factors are important considerations in specific cases because when political stability turns into instability it leads to unreliable deliveries, higher transaction costs and loss of competitiveness [56]. 
Song and Chatterjee (2010) in their study of achieving global supply-chain competitiveness studied 82 auto-component manufacturing companies of China and found that global competitiveness has altered the relationship between components suppliers and their customers. Global competitiveness depends on factors such as global quality, reliability of delivery and willingness to invest in retooling and this can be improved through collaborative learning and trust building. For trust building they mentioned major factors as reliability and consistency, openness and flexibility, ability and expertise, long-term orientation, benevolence and commitment, value congruence and social responsibility orientation. For learning process they mentioned organizational learning, learning platform, social learning and inter-personal learning contribute primarily [57].

Christopher et al. (2011) in their study of approaches to managing global sourcing risk divided global risk into 4 different groups as supply risk, process and control risk, environmental and sustainability risk, demand risk. Supply risk is the distribution of outcomes related to adverse events in inbound supply that affect the ability of the focal firm to meet customer demand (in terms of both quantity and quality) within anticipated costs and time like Supply disruptions, unreliable suppliers. Process and control risks are associated with the internal structure of the company i.e. inefficient supply teams in the organizations. Environmental and sustainability risks relates with pollution and emissions of greenhouse gases. Demand risk relates with uneven demand causing excess inventory. For such risk they mentioned solutions as follows.

Network re-engineering:- which means redesign of supply networks which are made through a good knowledge of upstream network as well as the downstream network.

Collaboration between global sourcing parties: - which includes transparency of information and cooperation with increased trust.

Agility: - which means quick response for unpredictable changes in demand or supply. Creation of a global sourcing risk management

Culture: - is the most logical strategy to mitigate risks in global sourcing but it requires conscious focus on managing and monitoring the risk profile which should be focused by the boardroom [22].

\subsubsection{Supplier Diversity}

Whitfield and Landerosd (2006) worked on issue of Supplier Diversity Effectiveness. Most minorities owned businesses are smaller in size and these firms often have a liability of newness and a higher risk of failure. This disadvantage can be reduced through partnership which will act as a helping hand for small firm to become supplier for big firm which in terms gives an opportunity to develop long-term mutually beneficial relationships. Here they found that such diversity in supplier base is beneficial for buyer. They also found that culture of organization plays major role on supplier diversity and organizations with constructive cultures for diversity had higher minority sourcing and organization with defensive culture have less minority sourcing [58].

Issue of smaller supplier's relationship and their development was also handled by Rhona and Ford (2006). In their study of interaction capability development of smaller suppliers in relationships with larger customers they examined types of interaction capabilities developed by smaller suppliers that enable them to cope and manage their relationships in better way with larger customers. They found that smaller supplier's interaction capability mainly comprising of four elements as human interaction, technological interaction, managerial systems interaction and cultural interaction capability. This gives guidelines to smaller suppliers regarding what is to be improved to work with big customers (buyers). Strong and well-established interaction capabilities developed by small suppliers can attract big customer's attention with opportunities for growth in conjunction with customers [59].

Henry and McMullen (2007) in their study of supplier diversity and supply chain management found that failure or success of minority suppliers in such competitive environment mainly depends upon developing their overall competences by being learning organizations. This happens with the help of intermediary organizations such as local supplier councils which will help to improve their competences and competitive edge. Supplier diversity can become a source of competitive advantage for corporations if such idea gets integrated into the overall corporate strategy and for successful occurrence of such strategy. Such initiative must have top management commitment, a supportive culture and the availability of people to promote the proposal. Suppliers, in turn, need to realize that their failure or success in this highly competitive environment depends on their ability to continually develop overall competences. They stated that suppliers can make use of intermediary organizations (such as local supplier councils) to improve their competences and competitive edge [60].

With this issue of supplier diversity Hokey Min (2009) studied supplier diversity program at Caterpillar. He found that supplier diversity program not only helps to reduce cost of sourcing but also helps to raise quality of product by supplier. He also mentioned that to go for supplier diversity programme buyer should make changes in culture i.e. buyer has to adapt constructive culture. While dealing with organizational culture main parameters he mentioned were leadership style, commitment from top management, shared values and business philosophy and these are key elements for implementing supplier diversity programme [61]. 


\subsubsection{Supplier Leanness}

Lean manufacturing is often associated with benefits such as reduced inventory, reduced time for manufacturing, increased quality, flexibility and satisfaction. Some of the practices of lean manufacturing include $5 \mathrm{~S}$ events, kaizen events, kanban, pull production, quick changeovers and value stream mapping. The $5 \mathrm{~S}$ are defined as sort (identify unnecessary equipment), straighten (arrange and label the area so all tools have a specified home), shine (clean the area and maintain equipment daily), standardize (establish guidelines and standards for the area) and sustain (maintain the established standards). Kaizen is continuous improvement process. Kanban uses a card to signal a need to produce or transport a container of raw materials or partially finished products to the next stage in the manufacturing process. Pull production is part of just in time system where manufacturing of product start when customer places order. Quick change over deals with minimum set up time. Value stream mapping is flow of material through the manufacturing process from the customer's point of view $[62,63]$.

Worley and Doolen (2006) in their study of the role of communication and management support in a lean manufacturing implementation found that not only management's support but also improved communication plays a significant role for lean strategy implementation. Lean manufacturing requires increased communication not only between shifts but also in every value stream. Supplier and buyer should have direct and clear method of communication for problem solving [64].

$\mathrm{Wu}$ (2003) in his study of Lean manufacturing from a perspective of lean suppliers made a comparative study between lean and non lean suppliers. He found that lean suppliers gain significant competitive advantages over non-lean suppliers in production systems, distribution systems, information communications, containerization, transportation systems, customer-supplier relationships and on-time delivery performance. So strategy of lean implementation helps to raise performance of firm with increased competitive advantage [65].

\section{Conclusion}

The purpose of this article is to find out which are factors or practices used by different firms for supplier development programmes. Now a day there is beneficial move from buyer in terms of relationship development for taking competitive advantage of supplier's innovativeness, technical capability and core competency. But there are still some gaps which can be taken forward for further research like,there is lack of studies in exploring how buyers can influence those suppliers which are not dependent upon them to participate in supplier training and product development programme, less work on strategies from buyers to encourage small scale industries (Criteria or Strategy available for promoting SME by buyers), less focus on supplier's perspective of how to influence buyer is less focused, fewer studies to define relationship among the parameters of supplier development (Like supplier training, supplier dependence, ESI, communication, trust), less study on intensity of buyer's involvement on the basis of life cycle growth of relationship and data collected in most of the studies is from buyer's perspective (Less study from supplier's perspective).

\section{Journal Papers:}

\section{References}

[1] Lau Antonio K.W., Supplier and Customer Involvement on New Product Performance: Contextual Factors and an Empirical Test from Manufacturer Perspective", Industrial Management \& Data Systems, 111(6), 2011, 910-942.

[2] Krause D. R., \& Ellram, L. M., Success factors in supplier development", International Journal of Physical Distribution \& Logistics Management, 27(1), 1997, 39-52.

[3] Watts, Charles A., Hahn, Chan K., Supplier Development Programs: An Empirical Analysis, International Journal of Purchasing and Materials Management, 29(2), 1993, 11-17

[4] Laugen B.T., Boer H., Acur N., Frick J., Best Manufacturing Practices, What Do The Best Performing Companies Do?, International Journal of Operations \& Production Management, 25(2), 2005, 131-150.

[5] Handfield R. B., Krause D.R., Scannell T.V., Monczka R.M., Avoid the Pitfalls in Supplier Development, Sloan Management Review, 41(2), 2000, 37-49

[6] Wagner S.M., Supplier Development Practices: An Exploratory Study, European Journal of Marketing, 40(5), 2006, 554-571

[7] Hartley Janet L., Jones Gwen E., Process Oriented Supplier Development: Building the Capability for Change, Journal of Supply Chain Management, 33(3), 1997, 24-29.

[8] Amad Che, Latifah, Hamid Abu Bakar Abdul, Norzafir Md Salleh, Chong Siong Choy, Adapting Buyer-Supplier Relationship Practices in Local Industry, Asian Academy of Management Journal, 13(2), 2008, 17-32.

[9] [Wagner S.M., Indirect and Direct Supplier Development: Performance Implications of Individual and Combined Effects, IEEE Transactions on Engineering Management, 57(4), 2010, 536-546.

[10] Aslan Imran, Elif Sis, Orhan Cinar, Cetin Bektas , Improving Short and Long Term Supplier Development Plan, Economics and Management, 16(1), 2011, 647-653.

[11] Wan Hasrulnizzam, Wan Mahmood, Nurulain Mat Tahar, Rahman Mohd Nizam Ab, Deros Baba Md, Supply Chain Enhancements through Product and Vendor Development Programme (PVD), Journal of Modeling in Management, 6(2), 2011, 164-177.

[12] Sánchez-Rodríguez, C., Hemsworth, D., Martínez-Lorente, Á. R., The effect of supplier development initiatives on purchasing performance: a structural model, Supply Chain Management: An International Journal, 10(4), 2005, $289-301$.

[13] Govindan, Kannan Devika A., Noorul Haq, Analyzing Supplier Development Criteria for an Automobile Industry, Industrial Management \& Data Systems, 110(1), 2010, 43-62. 
[14] Hahn C., Watts C., Kim K., Supplier Development Program: A Conceptual Model, Journal of Purchasing and Materials Management, 26(2), 1990, 2-7.

[15] Carr A.S., Pearson J.N., Strategically Managed Buyer-Supplier Relationships and Performance Outcomes, Journal of Operations Management, 17(5), 1999, 497-519.

[16] Cormican Kathryn, Cunningham Michael, Supplier Performance Evaluation: Lessons from a Large Multinational Organization, Journal of Manufacturing Technology Management, 18(4), 2007, 352-366.

[17] Hald Kim Sundtoft, Ellegaard Chris, Supplier Evaluation Processes: The Shaping and Reshaping of Supplier Performance", International Journal of Operations \& Production Management, 31(8), 2011, 888-910.

[18] Azadegan Arash, Benefiting from Supplier Operational Innovativeness: The Influence of Supplier Evaluations and Absorptive Capacity, Journal of Supply Chain Management, 47(2), 2011, 49-64.

[19] Schiele Holger, Veldman Jasper, Lisa Hettinger, Supplier Innovativeness and Supplier Pricing: The Role of Preferred Customer Status, International Journal of Innovation Management, 15(1), 2011, 1-27.

[20] Christopher Martin, Carlos Mena, Khan Omera,Yurt Oznur, Approaches to Managing Global Sourcing Risk, Supply Chain Management: An International Journal, 16(2), 2011, 67-81.

[21] Song Michael C, Benedetto Anthony Di, Supplier's Involvement and Success of Radical New Product Development in New Ventures, Journal of Operations Management, 26(1), 2008, 1-22.

[22] Twigg D., Managing Product Development within a Design Chain, International Journal of Operations \& Production Management. 18(5), 1998, 508-524.

[23] R., Humphreys P., Early Supplier Involvement in the Design Process: Lesson from the Electronics Industry, International Journal of Management Science, 32(3), 2004, 179 - 199.

[24] Jiao Yuan-Yuan, Du Jun, Jiao Roger J., Butler David L., Operational Implications of Early Supplier Involvement in Semiconductor Manufacturing Firms: A Case Study, Journal of Manufacturing Technology Management, 19(8), $2008,913-932$.

[25] Eisto Taneli, Holtta Venlakaisa, Mahlamaki Katrine, Kollanus Janne, Marko Nieminen, Early Supplier Involvement in New Product Development: A Casting-Network Collaboration Model, World Academy of Science, Engineering and Technology, 62(1), 2010, 856-886.

[26] Feng Taiwen, Sun Linyan, Zhang Ying, The Effects of Customer and Supplier Involvement on Competitive Advantage: An Empirical Study in China, Industrial Marketing Management, 39(1), 2010, 1384-1394.

[27] McIvor Modi, S.B., Mabert V.A., Supplier Development: Improving Supplier Performance through Knowledge Transfer, Journal of Operations Management, 25(1), 2007, 42-64.

[28] Kadir Abdul Kadir, On Kit Tam, Ali Hassan, Patterns of Supplier Learning: Case Studies in the Malaysian Automotive Industry, Asian Academy of Management Journal, 16(1), 2011, 1-20.

[29] Eamonn Ambrose, Donna Marshall, Brian Fynes, Daniel Lynch, Communication Media Selection in Buyer-Supplier Relationships, International Journal of Operations \& Production Management, 28(4), 2008, 360-379.

[30] Sanders Nada R., Chad W. Autry, David M. Gligor, The Impact of Buyer Firm Information Connectivity Enablers on Supplier Firm Performance: A Relational View, International Journal of Logistics Management, 22(2), 2011, 179-201.

[31] Sheth Jagdish N., Sharma Arun, Supplier Relationships: Emerging Issues and Challenges. Industrial Marketing Management, 26(2), 1997, 91-100.

[32] Smeltzer L., Meaning and Origin of Trust in Supplier-Buyer Relationship, Journal of Supply Chain Management, 33(1), 1997, 40-48.

[33] Johnston David A., David M. McCutcheon, F. Ian Stuart, Hazel Kerwood, Effects of Supplier Trust on Performance of Cooperative Supplier Relationships, Journal of Operations Management, 28(1), 2004, 23-38.

[34] Choi T.Y., Wu Z., Trends in Supply Networks: Theorizing Buyer-Supplier-Supplier Relationships, Journal of Supply Chain Management, 47(1), 2009, 8-25.

[35] Li Ling-yee, Relationship Learning at Trade Shows: Its Antecedents and Consequences, Industrial Marketing Management, 35(2), 2006, $166-177$.

[36] Petroni A., Panciroli B., Innovation as A Determinant of Suppliers' Roles and Performances: An Empirical Study in the Food Machinery Industry, European Journal of Purchasing \& Supply Management, 8(3), 2002, 135-149.

[37] Goffin Keith, Fred Lemke, Marek Szwejczewski, An Exploratory Study of Close Supplier-Manufacturer Relationships, Journal of Operations Management, 24(2), 2006, 189-209.

[38] McCutcheon D., Stuart F.I., Issues in the Choice of Supplier Alliance Partners, Journal of Operations Management, 18(3), 2000, 279-301.

[39] Lambert Douglas M., Margaret A Emmelhainz, John T Gardner, Developing and implementing supply chain partnerships, International Journal of Logistics Management, 7(2), 1996, 1-17.

[40] Li Wenli, Humphreys Paul K., Andy C.L. Yeung, T.C. Edwin Cheng, The Impact of Specific Supplier Development Efforts on Buyer Competitive Advantage: An Empirical Model, International Journal of Production Economics, 106(1), $2007,230-247$.

[41] Gullett Josh, Loc Do, Maria Canuto-Carranco, Mark Brister, Shundricka Turner, Cam Caldwell, The Buyer-Supplier Relationship: An Integrative Model of Ethics and Trust, Journal of Business Ethics, 90(1), 2009, 329-341.

[42] Hald Kim Sundtoft, Carlos Cordon, Thomas E. Vollmann, Towards an Understanding of Attraction in Buyer-Supplier Relationships, Industrial Marketing Management, 38(8), 2009, 960-970.

[43] Ana Gueimonde-Canto, Javier Gonzalez-Benito, Jose Manuel Garcia-Vazquez (2011), Competitive Effects of Co-Operation with Suppliers and Buyers in the Sawmill Industry, Journal of Business \& Industrial Marketing, 26(1), $2011,58-69$.

[44] Wagner S.M., Supplier development and the relationship life-cycle, International Journal of Production Economics, 29(1), 2011, 277-283

[45] Brown Andrew D., Inger Boyett, Phil Robinson, The Dynamics of Partnership Sourcing, Leadership \& Organization Development Journal, 15(7), 1994, 15-18.

[46] Wu Hung-Yi, Yueh-Ju Lin, Fei-Liang Chien, Yu-Ming Hung, Study on Relationship among Supplier Capability, Partnership and Competitive Advantage in Taiwan's Semiconductor Industry", International Journal of Electronic Business Management, 9(2), 2011, 122-138.

[47] Sanchez, R. and Mahoney, J.T., Modularity, Flexibility, and Knowledge Management in Product and Organization Design, Strategic Management Journal, 17(Winter Special Issue), 1996, 63-76.

[48] Howard Mickey, Squire Brian, Modularization and the Impact on Supply Relationships, International Journal of Operations \& Production Management, 27(11), 2007, 1192-1212.

[49] Squire Brian, Paul D. Cousins, Benn Lawson, Steve Brown, The Effect of Supplier Manufacturing Capabilities on Buyer Responsiveness: The Role of Collaboration, International Journal of Operations \& Production Management, 29(8), 2009, 766788 . 
[50] Joongsan Oh, Seung-Kyu Rhee, Influences of Supplier Capabilities and Collaboration in New Car Development on Competitive Advantage of Carmakers, Management Decision, 48(5), 2010, 756-774.

[51] Trent Robert J., Monczka Robert M., Understanding Integrated Global Sourcing, International Journal of Physical Distribution \& Logistics Management, 33(7), 2003, 607-629.

[52] Takala Josu, Jarkko Hirvela Yang Liu, Dusan Malindzak, Global Manufacturing Strategies Require "Dynamic Engineers? Case Study in Finnish Industries, Industrial Management \& Data Systems, 107(3), 2007, 326-344.

[53] Oke Adegoke, Arnold Maltz, Poul Erik Christiansen, Criteria for Sourcing from Developing Countries", Strategic Outsourcing: An International Journal, 2(2), 2009, 145-164.

[54] Song Hua, Chatterjee Samir Ranjan, Achieving Global Supply-Chain Competitiveness: Evidence from the Chinese Auto Component Sectors, Chinese Management Studies, 4(2), 2010, 101-118.

[55] Whitfield G. and Landeros R., Supplier Diversity Effectiveness: Does Organizational Culture Really Matter? Journal of Supply Chain Management, 42(1), 2006, 16-28

[56] Rhona Johnsen E., Ford David, Interaction Capability Development of Smaller Suppliers in Relationships with Larger Customers, Industrial Marketing Management, 35(8), 2006, 1002-1015.

[57] Henry Adobor, McMullen Ronald, Supplier Diversity and Supply Chain Management: A Strategic Approach, Business Horizons, 50(1), 2007, 219-229.

[58] Hokey Min, The Best-Practice Supplier Diversity Program at Caterpillar, Supply Chain Management: An International Journal, 14(3), 2009, 167-170.

[59] Worley J.M., Doolen T.L., The Role of Communication and Management Support in a Lean Manufacturing Implementation, Management Decision, 44(2), 2006, 228-245.

[60] Wu Yen Chun, Lean Manufacturing: A Perspective of Lean Suppliers, International Journal of Operations \& Production Management, 23(11), 2003, 1349-1376.

Books:

[61] Smith G, Managing to Succeed: Strategies and Systems for Manufacturing Businesses (London: prentice hall international, 1995).

[62] Simchi-Levi D., Kaminsky P., Simchi- Levie E., Designing and Managing the Supply Chain-Concepts, Strategies and Case Studies (McGraw Hill, New Delhi).

[63] Hosmer L. T., The Ethics of Management (6th Edition McGraw-Hill, New York, 2008).

[64] Womack J.P., Jones D.T. and D Roos, The Machine that Changed the World: The Story of Lean Production (Harper Collins, New York, 1990).

[65] Nicholas J., Competitive Manufacturing Management (Irwin/McGraw-Hill, New York, 1998). 